\title{
Anticorrosive Properties of Hot-Dip Galvanized Weathering Steel in Atmospheric Exposure
}

\author{
Elber Vidigal Bendinelli, Felipe Garcia Nunes, Alberto Pires Ordine \\ Corrosion Laboratory, Electric Energy Research Centre-Cepel, Rio de Janeiro, Brazil \\ Email: ordine@cepel.br
}

How to cite this paper: Bendinelli, E.V., Nunes, F.G. and Ordine, A.P. (2020) Anticorrosive Properties of Hot-Dip Galvanized Weathering Steel in Atmospheric Exposure. Materials Sciences and Applications, 11, 611-625.

https://doi.org/10.4236/msa.2020.119041

Received: July 22, 2020

Accepted: September 6, 2020

Published: September 9, 2020

Copyright () 2020 by author(s) and Scientific Research Publishing Inc. This work is licensed under the Creative Commons Attribution-NonCommercial International License (CC BY-NC 4.0).

http://creativecommons.org/licenses/by-nc/4.0/

\begin{abstract}
Hot-dip galvanized steel is one of the most used materials in equipment and metallic structures of the Brazilian electric sector. Although carbon steel is the main substrate in the galvanizing hot-dip process, recently, weathering steel has been used as an alternative material to be galvanized. In the transmission line segment of the Brazilian electric sector, for instance, compact towers made of galvanized weathering steel have been installed to conduct energy through urban sites. It is well known that weathering steel, depending on wet and dry cycles and on the pollutants present in the atmosphere, develops a protective patina made of its corrosion products. The patina is dense and strongly adhered to the substrate, blocking the active surface and, thus, reducing the corrosion rate of the base metal. However, when the weathering steel is galvanized, the substrate surface has a layer of zinc and zinc-iron intermetallic alloys. When the sacrificial layer is consumed by atmospheric corrosion, critical questions remain to be answered regarding the underlying substrate. Will the patina of weathering steel be formed? In what condition? Does the hot-dip galvanizing process modify the weathering steel microstructure? The present work carried out an experimental research to shed light on the anticorrosive behavior of hot-dip galvanized weathering steel, after the zinc layer is corroded. This was done by a controlled pickling process, where the zinc layer was removed simulating its consumption during real corrosion processes. The results, obtained through electrochemical techniques and different accelerated corrosion tests, showed that galvanizing weathering steel is a promising technology to enhance the lifetime of structures used in the Brazilian electric sector.
\end{abstract}

\section{Keywords}

Atmospheric Corrosion, Galvanized Weathering Steel 


\section{Introduction}

Weathering steel is widely used as construction material for metallic structures under atmospheric exposure. Due to its excellent anticorrosive properties, the application of organic coatings is dispensable, reducing maintenance costs when compared with conventional carbon steel coated structures [1]. Weathering steel contains alloying elements, such as $\mathrm{Cu}, \mathrm{Cr}, \mathrm{P}$ and $\mathrm{Ni}$, that favors the formation of a compact layer of corrosion products on the metallic surface over time [2] [3]. This rust layer, also known as patina, is thick, dense and highly adherent to the substrate. Owing to its passive properties, the patina effectively isolates the underlying steel from aggressive media, reducing the corrosion rate and protecting the substrate from material consumption and further degradation [2] [4] [5].

The protective features of the patina are usually attributed to the formation of corrosion products mainly comprised of $\alpha$-FeOOH. The structure of such rust layer is different from the usual layer of corrosion products formed when carbon steel is exposed to the atmosphere, as the latter is less compact and presents voids and microcracks, being unable to protect the steel. The presence of higher $\mathrm{Cu}$ and $\mathrm{Cr}$ contents accelerates the formation of the compact and stable $\alpha$-FeOOH structures [2] [3]. Furthermore, addition of Ni, P, among other alloying elements, also contributes to the improvement of corrosion resistance of weathering steels [2] [3] [4]. Besides the addition of alloying elements, in order to have proper conditions for the formation of the protective corrosion products layer, weathering steel must be used in urban sites and be subjected to wet and dry cycles. Indeed, in atmospheres containing sulphur compounds, the corrosion rate of carbon steel shows appreciable increase, whereas weathering steel corrodes significantly slower, owing to the patina formation [4] [5].

Hot-dip galvanizing process is broadly employed to produce equipment and structures for the Brazilian electric sector, such as in power plants and transmission lines segments. Zinc is anodic to the steel and functions as a sacrificial metal. As long as there is enough zinc to protect the steel, substrate corrosion is avoided, even when aggressive media are in direct contact with the base metal. Furthermore, the corrosion rate of zinc is slow in most natural environments. In the case of climatic exposure, this is generally attributed to the formation of zinc hydroxides and carbonates that produce a surface blocking effect [6] [7]. Therefore, in Brazil, it is possible to find galvanized structures in transmission lines under atmospheric exposure that are 50 years old and still preserved.

Regarding anticorrosive methods, weathering steel and galvanized steel have their own individual application. The latter is most produced from carbon steel, a cost-effective material, considering other steel alloys. The approach to combine both methods of protection by galvanizing the weathering steel is a recent technology in Brazil. In the electric sector of the country, hot-dip galvanized weathering steel is used in compact towers of transmission lines. These towers have been installed mainly in urban sites. Due to its mechanical properties, one ad- 
vantage of its use is the possibility of working with lighter structures, when compared with conventional galvanized carbon steel towers. Furthermore, producers claim that, in the future, when the zinc layer is corroded, hot-dip galvanized weathering steel will have an extra anticorrosive property. That is the formation of the patina from the corrosion products of the weathering steel.

Although, in theory, this is an advantage for galvanizing weathering steel, in practice, the real anticorrosive properties of weathering steel after the zinc layer is corroded remains to be addressed. This fact was the fundamental drive for the development of the experimental research presented in this paper. Hot-dip galvanized weathering steel was pickled in a controlled way to remove only the zinc layer, simulating a corrosion process of the metallic coating in real conditions. Following that, it was investigated if the anticorrosive properties of the weathering steel were preserved in different aggressive media, compared to the weathering steel that was not galvanized. Carbon steel, pure zinc and traditional galvanized steel (having carbon steel as substrate) were also included in the accelerated corrosion tests. Electrochemical methods and optic microscopy analysis were carried out to complement the study. All results allowed for a better understanding of the anticorrosive behavior of hot-dip galvanized weathering steel, in different aggressive conditions. It was possible to determine the corrosion rate of the materials and obtain valuable information on their expected lifetime.

\section{Materials and Methods}

Table 1 shows the materials investigated in this work and their designation in the paper. The galvanized samples were produced in the same batch, by an industrial hot-dip galvanizing process. Samples were rectangular plates with thickness of $6.4 \mathrm{~mm}$ and had distinct surface areas, depending on the test. Samples with the lowest area $\left(5 \mathrm{~cm}^{2}\right)$ were tested by electrochemical methods. Samples with the highest area $\left(150 \mathrm{~cm}^{2}\right)$ were subjected to accelerated corrosion tests.

The pickling process consisted of immerging the galvanized weathering steel in a $50 \%$ hydrochloric acid solution, containing $3.5 \mathrm{~g} / \mathrm{L}$ of tetramine hexamethylene, a corrosion inhibitor to avoid substrate attack [8]. Samples were immerged and kept in this way until all hydrogen bubbling stopped, indicating that the zinc layer was completely removed.

Table 1. Materials and their designation.

\begin{tabular}{cc}
\hline Material & Designation \\
\hline Carbon steel & CS \\
Galvanized steel (from carbon steel) & GCS \\
Weathering steel & WS \\
Galvanized weathering steel & GWS \\
Galvanized weathering steel after removal of the zinc layer & WSRZ
\end{tabular}


The electrochemical methods were accomplished in a conventional three electrode cell, where the working electrode was the material to be investigated. A saturated calomel electrode was used as a reference and graphite rods as counter electrodes. The open circuit potential (OCP) was monitored with time and polarization techniques were applied with the aid of a potentiostat. Anodic polarization curves were obtained in $10^{-4} \mathrm{~mol} / \mathrm{L}$ sodium bisulphite solution $\left(\mathrm{NaHSO}_{3}\right)$ to an overpotential of $0.3 \mathrm{~V}$ in relation to the open circuit potential and at a scan rate of $0.1 \mathrm{mV} / \mathrm{s}$. Anodic voltammetric stripping was applied from $-1.00 \mathrm{~V}$ to $-0.50 \mathrm{~V}$ at a scan rate of $0.005 \mathrm{mV} / \mathrm{s}$. In this case, the saline solution contained $3.42 \mathrm{~mol} / \mathrm{L}$ of $\mathrm{NaCl}$ and $0.35 \mathrm{~mol} / \mathrm{L}$ of $\mathrm{ZnSO}_{4} \cdot 7 \mathrm{H}_{2} \mathrm{O}$, at a $\mathrm{pH}$ equal to 5 . This technique was accomplished to dissolve in a controlled manner the intermetallic phases of galvanized steel [9] [10].

Cross-sectional images of the galvanized layer were obtained using an optical microscope Olympus GX 71. The plates were cut-off, embedded in resin and polished to a fine surface finish. In order to reveal the metallic microstructure, samples were etched in proper solutions. The first etching solution contained $200 \mathrm{~g} / \mathrm{L}$ of $\mathrm{CrO}_{3}$ and $15 \mathrm{~g} / \mathrm{L}$ of $\mathrm{Na}_{2} \mathrm{SO}_{4}$. In a second etching step, the solution contained $200 \mathrm{~g} / \mathrm{L}$ of $\mathrm{CrO}_{3}$.

Two accelerated corrosion tests were conducted, namely CEBELCOR and Kesternich tests. The former was developed by the Belgian Corrosion Research Center [11]. It consists of simulating the action of natural agents (wet and dry cycle, atmospheric pollutants) in a cyclic manner to promote the formation of the protective layer of corrosion products in weathering steel. Figure 1 presents the arrangement of the test, where samples were fixed in a rotating axis. In this way, they were wetted by a $10^{-4} \mathrm{~mol} / \mathrm{L}$ solution of $\mathrm{NaHSO}_{3}$ during the wet cycle and were submitted to the heat of an incandescent lamp at $40^{\circ} \mathrm{C}$ during the dry cycle. A complete cycle took one hour. This test was carried out for a period of 270 days. Samples were taken from the test to determine their corrosion rate after 90,180 and 270 days.

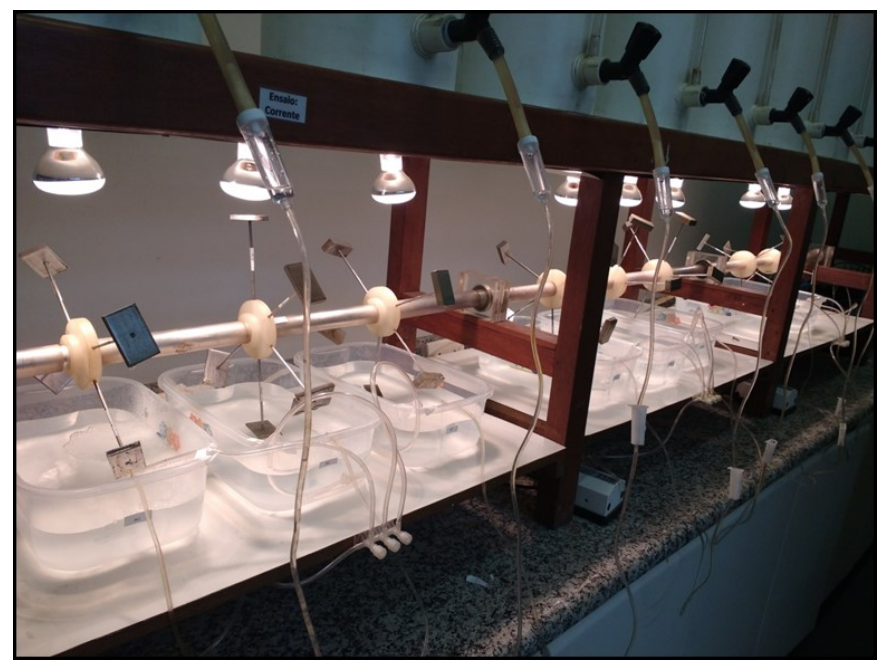

Figure 1. Experimental arrangement of the CEBELCOR test. 
The Kesternich test was conducted according to ASTM G87 Standard [12], using $0.5 \mathrm{~L}$ of sulphur dioxide, at $40^{\circ} \mathrm{C}$ in a $100 \%$ relative humidity chamber, simulating an industrial atmosphere. Each cycle was composed of $8 \mathrm{~h}$ in the former condition and $16 \mathrm{~h}$ in laboratory climate $\left(24^{\circ} \mathrm{C}\right.$ and $55 \%$ of relative humidity). Tests were performed up to 60 cycles and samples were removed from the chamber each 15 cycles to determine their corrosion rate.

A natural corrosion test was carried out in an urban site, located at the Electric Energy Research Centre-Cepel, in Rio de Janeiro city, Brazil. The corrosivity degree of this site was previously classified as medium to carbon steel [13]. Samples were exposed for 270 days in the site and parts of them were withdrawn after 90,180 and 270 days to determine their corrosion rate at different times of exposure.

The corrosion rate of the samples, after all tests, was determined by mass loss procedures according to ASTM G1 and ISO 8407 Standards [14] [15].

This was an experimental research developed in the Corrosion Laboratory of Cepel, the Electric Research Centre of Brazil. The Laboratory was founded in 1974 and has a vast experience in the study of corrosion processes, electrochemical techniques, coatings technology, among other corrosion control methods.

\section{Results and Discussion}

The alloying elements present in the materials were determined by chemical analysis. Table 2 shows the results of the main elements that have some influence in patina formation and galvanized layer deposition. After dissolving the samples, the following methods were used to quantify chemical elements: direct combustion and infrared analysis, for carbon (C); gravimetric analysis and spectrophotometry of chemical absorption for silicon (Si), chromium (Cr), copper $(\mathrm{Cu})$ and nickel $(\mathrm{Ni})$; volumetric analysis for phosphorus $(\mathrm{P})$. Remaining elements for each alloy correspond to iron (greater than 97\%) and other minor elements (less than 1.3\%), such as sulphur (S), manganese (Mn) and molybdenum (Mo). Although some alloying elements content slightly diverged from typical standardized values in weathering steels [16] [17], this aspect did not compromise the performance of this material, as will be presented ahead. The higher contents of the elements were indeed responsible for better anticorrosive properties for weathering steel. Another interesting observation, by Table 2, is the fact that the element contents of WS and WSRZ samples were very similar to

Table 2. Element content in the alloys.

\begin{tabular}{ccccccc}
\hline \multirow{2}{*}{ Sample } & \multicolumn{7}{c}{ Element content (\%) } \\
\cline { 2 - 7 } & $\mathrm{C}$ & $\mathrm{Si}$ & $\mathrm{P}$ & $\mathrm{Cr}$ & $\mathrm{Cu}$ & $\mathrm{Ni}$ \\
\hline CS & 0.150 & 0.03 & 0.010 & 0.020 & $<0.010^{\mathrm{a}}$ & $<0.010^{\mathrm{a}}$ \\
WS & 0.131 & 1.10 & 0.024 & 0.190 & 0.080 & 0.020 \\
WSRZ & 0.127 & 1.02 & 0.036 & 0.185 & 0.127 & 0.014 \\
\hline
\end{tabular}

${ }^{a}$ Lower than the detection limit (0.010) of the technique. 
each other. This shows that the hot-dip galvanizing process did not affect the weathering steel chemical composition, which is important to assure that the conditions for patina formation remain unchanged.

The mass of zinc per area in galvanized samples were determined by a mass loss methodology according to ISO 1460 Standard [8]. After determining the coating mass by the standardized experimental procedure, average coating thicknesses were calculated using the specific mass of zinc, also according to the mentioned standard. As this is a destructive test, this procedure was carried out for a single sample of GCS and GWS. Remaining galvanized samples thicknesses were measured with the aid of a magnetic gauge. Results are presented in Table 3.

It is observed that, even though the galvanizing process was the same for both samples (GCS and GWS), galvanizing the weathering steel produced a thicker zinc layer. This behaviour has already been reported in the literature [6] [18] [19]. Silicon is responsible for raising the reactivity of the steel during the hot-dip galvanizing processes, changing the growth kinetics of the intermetallic phases. This is commonly known as Sandelin effect, justifying the greater zinc thickness present for the weathering steel, given its higher Si content [6].

Figure 2 presents the cross-section microscopic images of GCS and GWS samples.

By the microscopic images, it is possible to confirm that both materials presented galvanized layers with similar morphology. Intermetallic phases are present, which are characteristic of the metallurgical interaction of zinc and iron during the galvanizing process. Gamma $(\Gamma)$ phase is located closer to the substrate. Delta $(\delta)$ phase has larger crystals and is located between gamma $(\Gamma)$ and zeta (ל) phases. The latter is known to present thinner crystals oriented vertically to the surface. On the surface, it is possible to find a very thin layer of the eta ( $\eta$ ) phase, which is composed of nearly pure zinc. Zinc content is higher in the top surface and is around 75\% near the substrate, due to the diffusion of iron through the layer during the hot-dip galvanizing process. The iron concentration in the phases decreases from the bottom to the top of the galvanized layers. The average percentages of iron present in the phases are the following: gamma, $25 \%$, delta, $10 \%$, zeta, $6 \%$, eta, $0.1 \%[6]$.

Three different electrochemical techniques were carried out: the measurement of the open circuit potential (OCP) as function of time, anodic polarization curves and anodic voltammetric stripping. Figure 3 shows the results of the OCP during 420 days of experiment, in reference to the saturated calomel electrode.

Table 3. Mass of zinc in the galvanized samples.

\begin{tabular}{cccc}
\hline Sample & $\begin{array}{c}\text { Coating mass } \\
\left(\mathrm{g} / \mathrm{m}^{2}\right)\end{array}$ & $\begin{array}{c}\text { Average coating thickness } \\
\text { calculated from }[8](\mu \mathrm{m})\end{array}$ & $\begin{array}{c}\text { Average coating thickness measured } \\
\text { with magnetic gauge }(\mu \mathrm{m})\end{array}$ \\
\hline GCS & 629 & 88 & $89 \pm 7$ \\
GWS & 1039 & 146 & $147 \pm 21$ \\
\hline
\end{tabular}




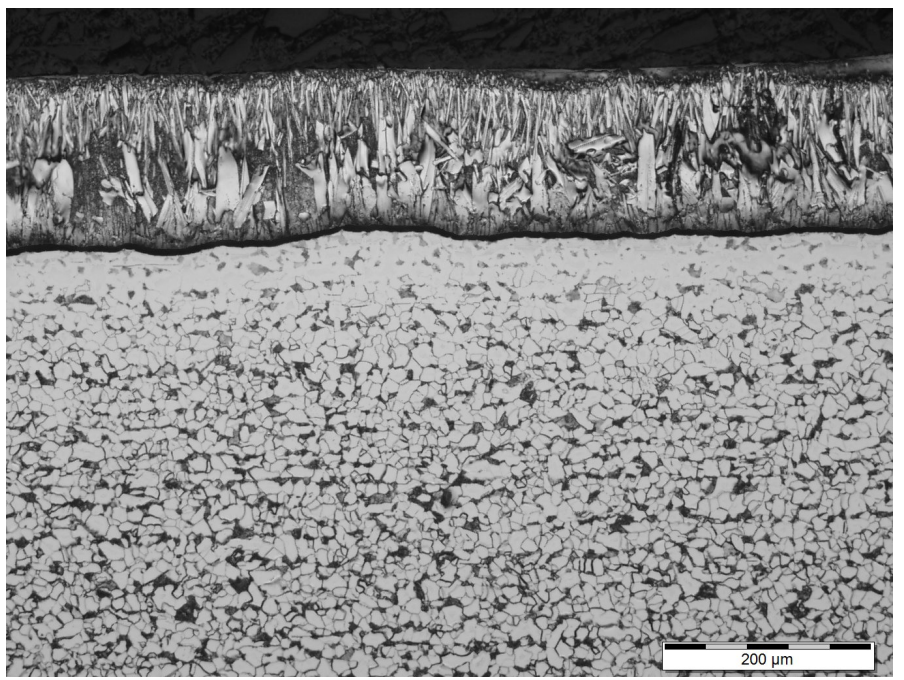

(a)

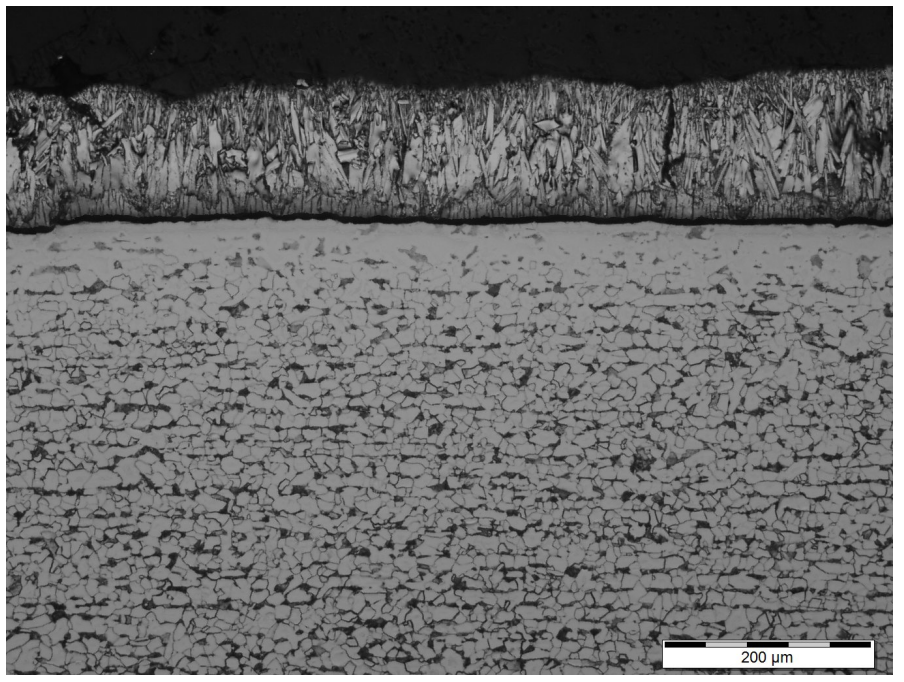

(b)

Figure 2. Microscopic images of galvanized (a) carbon steel and (b) weathering steel.

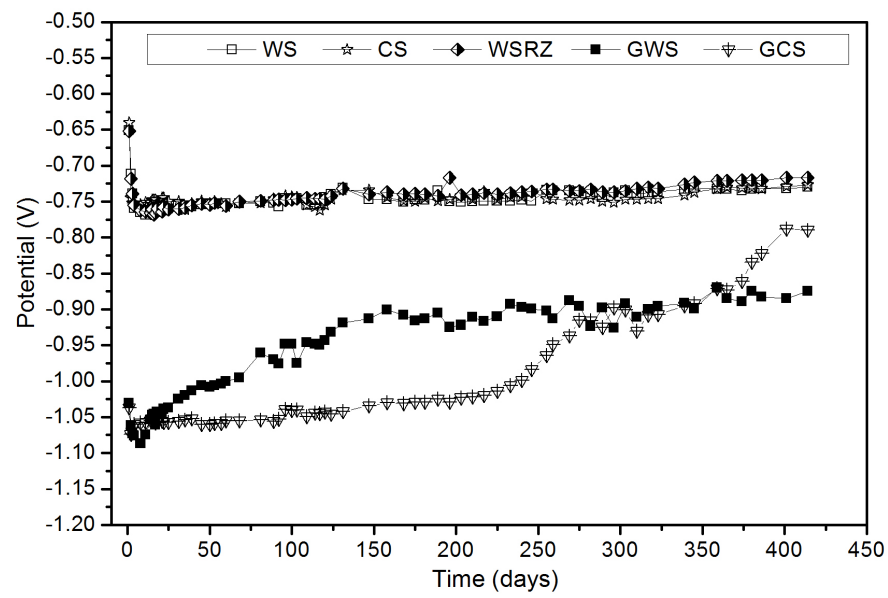

Figure 3. Electrode potential as function of time in immersion condition at a $3.5 \%$ sodium chloride solution. 
In the case of iron alloys samples (CS, WS and WSRZ), the potential registered was around $-750 \mathrm{mV}$, which is related to the corrosion of iron. As WSRZ presented the same behaviour, this is a strong indication that there was no zinc left in its surface after pickling, as the corrosion potential of zinc in this system is known to be around $-1000 \mathrm{mV}$. If there was zinc left in the WSRZ surface, its potential would be lower. Comparing the changes in potential with time of WS and WSRZ, an identical pattern can be observed. This suggests that the evolution of the corrosion process is similar for both materials.

As for the galvanized samples, monitoring the OCP with time is a way to access the transformations taking place at the surface level. As corrosion progresses, the surface composition is being constantly modified, which in turn also causes changes in potential. Initially, the potential of the system corresponds to the corrosion potential of zinc, as the outer layer is virtually pure in this element. The consumption of this layer exposes the intermetallic phases to the solution, allowing their dissolution as well. As these layers have a higher iron content, the mixed potential of the system naturally shifts toward greater values, closer to the corrosion potential of iron. In other words, zinc-rich layers are being consumed, exposing the iron rich layers underneath, until all the zinc phases have sacrificed themselves, leaving the metal substrate unprotected. When this happens, corrosion of iron starts and the potential values will be the same as those registered for iron alloys, around $-750 \mathrm{mV}$.

Analysing the evolution of potential for the galvanized samples (GWS and GCS), up to 25 days, the potential of both remained near $-1060 \mathrm{mV}$, which is due to the eta phase in the surface. As time passed, the potential of GWS increased faster than that of GCS, suggesting that the corrosion of zinc is more accelerated in the weathering steel. The potential values of both materials matched again after approximately 270 days of experiment, overlapping each other for another 90 days. At approximately 360 days of experiment, the potential of GCS tended to increase faster than that of GWS. By the end of the test, after 420 days, none of the galvanized samples reached the potential due to iron corrosion, which means that both still had zinc in the surface protecting the substrate. But, the galvanized carbon steel (GCS) had less zinc left in the surface than the galvanized weathering steel (GWS), because the potential of the former was higher, $-800 \mathrm{mV}$, compared to the potential of the latter, $-880 \mathrm{mV}$. After a long time of test, this behaviour was expected as GCS has a thinner layer of zinc than GWS.

Figure 4 presents the results of anodic polarization curves in sodium bisulphite solution. Assuming that the oxidation reactions were under charge transfer control in the system studied, it is known that, as the potential increases, the interfacial current is exponentially activated by the overpotential, as defined by the activation polarization and the Butler-Volmer equation [20]. The electrochemical nature of such process allows for the correlation between the current and the kinetics of the reaction. In other words, the higher the anodic current values, the faster are the oxidation reactions taking place. 


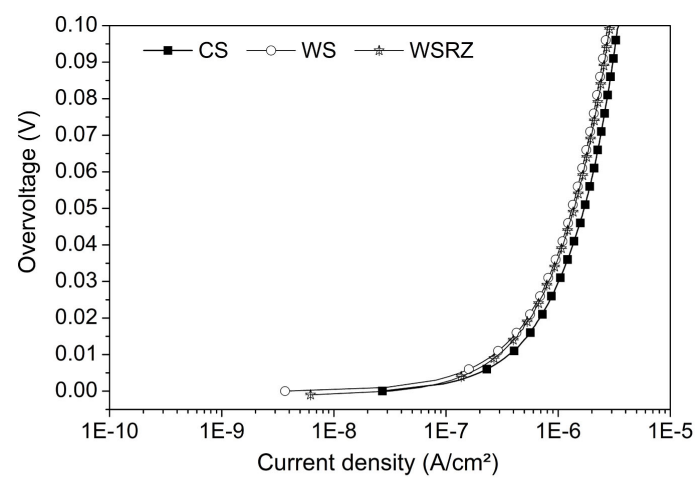

(a)

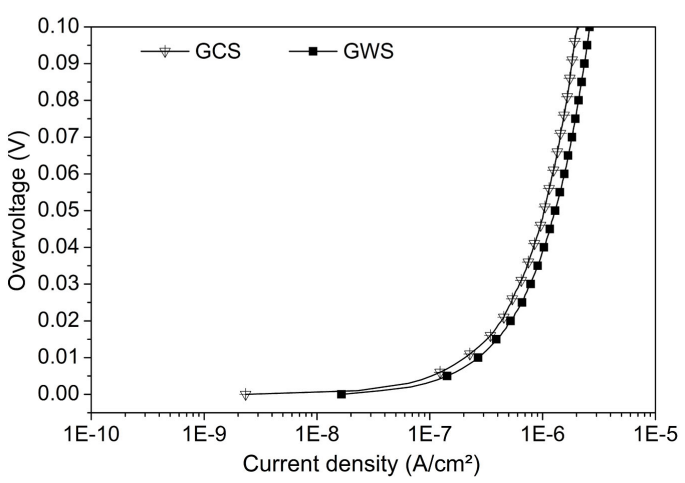

(b)

Figure 4. Anodic polarization curves of the materials investigated: (a) naked metals; (b) galvanized steels.

The sulphite solution was used to simulate aggressive environment containing sulphur compounds, known to favour the formation of the protective oxide layer in weathering steels. Despite that, there was no appreciable difference between the anodic curves of CS, WS and WSRZ, indicating similar oxidations kinetics for such materials. The continuous immersion condition and the short interaction time with solution may not have allowed the formation of any protective layer for WS and WSRZ, justifying the similar performance between these materials and CS. Besides the proper pollutant agent, dry and wet cycles are fundamental for the weathering steel to form its patina. This will be evident with the results from CEBELCOR tests. Nevertheless, the fact that WS and WSRZ presented the same curves shows that the galvanizing process did not affect the weathering steel surface and its corrosion behaviour after the zinc layer is consumed. This is an important aspect that contributes to the use of galvanized weathering steel. These results will be confirmed by the accelerated corrosion tests.

Regarding galvanized samples, GCS and GWS, slightly lower currents can be seen for GCS, especially in the region of low overvoltage, as the current density values for GCS were one order of magnitude lower than for GWS. These observations are related to slower oxidation kinetics in the case of GCS. This result agrees with the evolution of the potential with time showed in Figure 3, as the 
GWS presented, initially, a steeper rise in the potential curve. However, it is worth noting that the difference is subtle, and whether there is a distinction in performance between GCS and GWS has to be confirmed by corrosion tests.

Figure 5 presents the anodic voltammetric stripping curve of the galvanized carbon steel. The experiment started at the OCP, which was around $-1060 \mathrm{mV}$. Potential was increased at a very low rate, allowing for the sequential dissolution of each phase, resulting in the appearance of peaks in the curves. Each peak expresses the corrosion (or consumption) of one or more intermetallic phase. The area and intensity of each peak are related to the thickness (quantity) of one or more intermetallic phases. In Figure 5, the first anodic peak formed presented a maximum value at $-950 \mathrm{mV}$. It is attributed to the preferential dissolution of mostly the zeta phase. As the eta phase is very thin, its dissolution happens almost simultaneously with the zeta phase. The second peak formed at the range from $-900 \mathrm{mV}$ to $-770 \mathrm{mV}$ can be related to the preferential dissolution of the delta phase. A third peak associated to the oxidation of the gamma phase was registered with a maximum peak value of $-730 \mathrm{mV}$. As this phase has the lowest content of zinc, the peak is the smallest. Moreover, the smallest area around the peak is due to the thinnest thickness of the phase [9] [10] [21].

Anodic stripping of GWS sample is shown in Figure 6. Compared to GCS, in GWS the current values were three times higher, mainly because GWS has a zinc layer with greater thickness. Moreover, the peaks are finely separated and defined in Figure 6, markedly different from Figure 5. Therefore, besides a higher amount of zinc to be oxidized, GWS seems to have intermetallic phases with electrochemical dissolution peaks better defined. These results, along with the optic micrographs of the galvanized layer, confirm that all the intermetallic phases were formed during the process, albeit in a different proportion for each material. The electrochemical behavior of the materials is a complementary result to their anticorrosive performance in the corrosion tests.

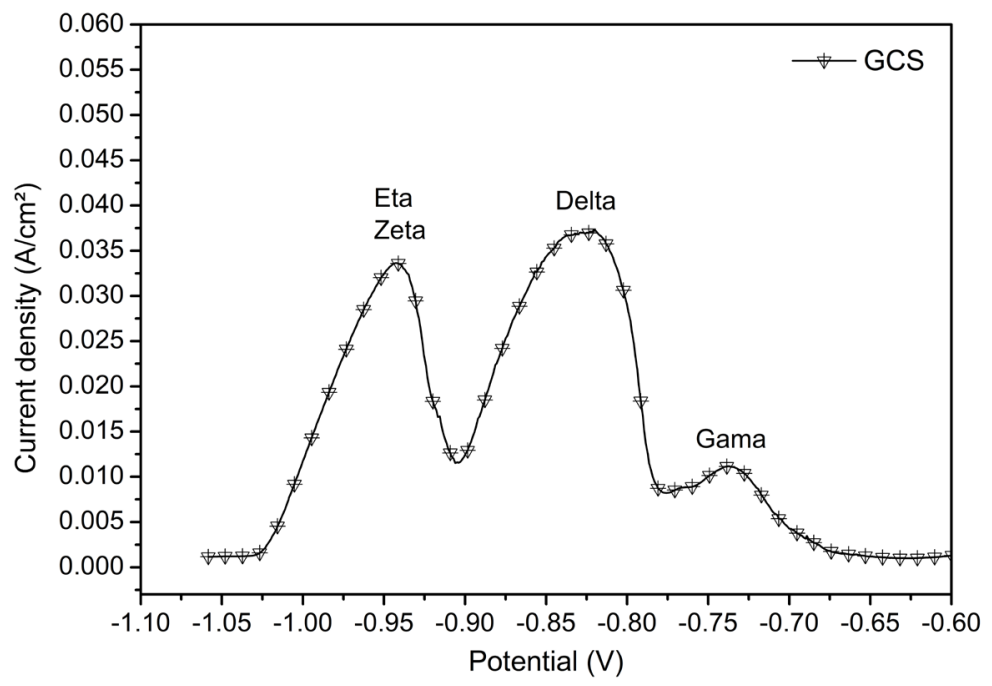

Figure 5. Anodic voltammetry of GCS. 


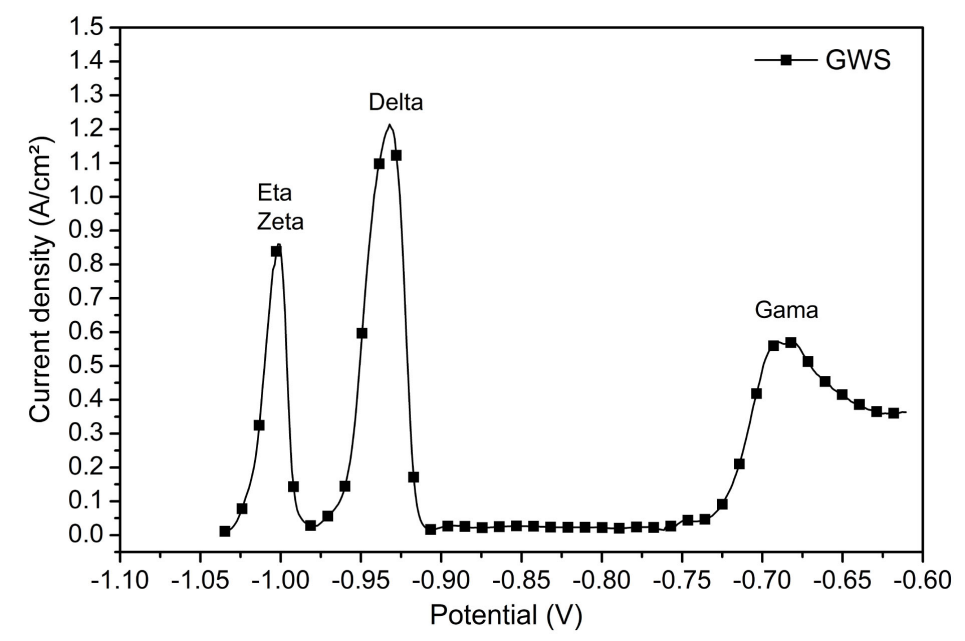

Figure 6. Anodic voltammetry of GWS.

The corrosion tests were carried out with the iron alloys (CS, WS and WSRZ) and pure zinc $(\mathrm{Zn})$. The latter was included in the tests as a reference. It is shown that corrosion rates are always very low with zinc, regardless the test. Thus, that would be the behaviour expected initially for the galvanized samples (GCS and GWS), during the consumption of the eta phase. The aim of the tests was to evaluate the corrosion rate of the weathering steel when all the zinc is corroded, exposing the substrate (sample WSRZ). Samples CS and WS were also used as reference materials (the base iron alloys prior to the galvanizing process) for comparison purposes. Figures 7-9 present the results of the corrosion tests in the different media studied.

CEBELCOR is known to be the most suitable accelerated test to simulate the natural condition for the formation of the patina in weathering steel. Coherently, results in Figure 7 point out much lower corrosion rates for WS and WSRZ samples than for CS. This suggests that the protective patina was properly formed during the test, isolating the steel from the aggressive media, resulting in lower corrosion rates for WS and WSRZ. Besides, values for WS and WSRZ were approximately the same, at about $0.05 \mathrm{~mm}$ /year. Therefore, after the zinc layer is corroded in GWS, it is expected that the weathering steel will keep its original anticorrosive properties.

Comparing the accelerated tests, corrosion rates were much higher in Kesternich test (Figure 8), which simulates an industrial atmosphere. This is a very corrosive environment to iron alloys [20], so the corrosion rate tended to increase fast and, after 10 cycles, it reached $5 \mathrm{~mm}$ /year for carbon steel. Both WS and WSRZ samples presented the same corrosion rate, at about $4 \mathrm{~mm} /$ year. Again, the galvanizing process did not cause any harm to the anticorrosive properties of the weathering steel. In the case of zinc, its corrosion rate increased continuously, reaching $1.5 \mathrm{~mm} /$ year by the end of the test.

The test carried out in natural condition (Figure 9) once again reveals lower corrosion rates of the weathering steels, compared to the carbon steel. Moreover, the behaviour of WS and WSRZ were markedly the same. 


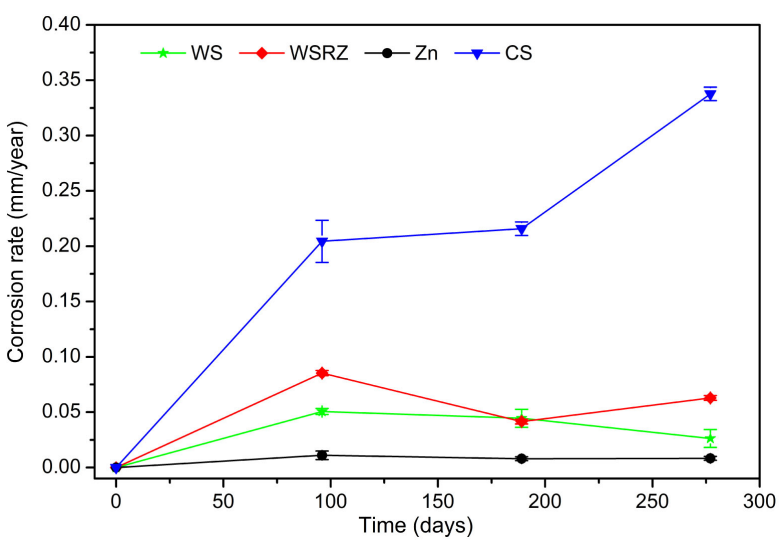

Figure 7. Corrosion rate of the materials in CEBELCOR test.

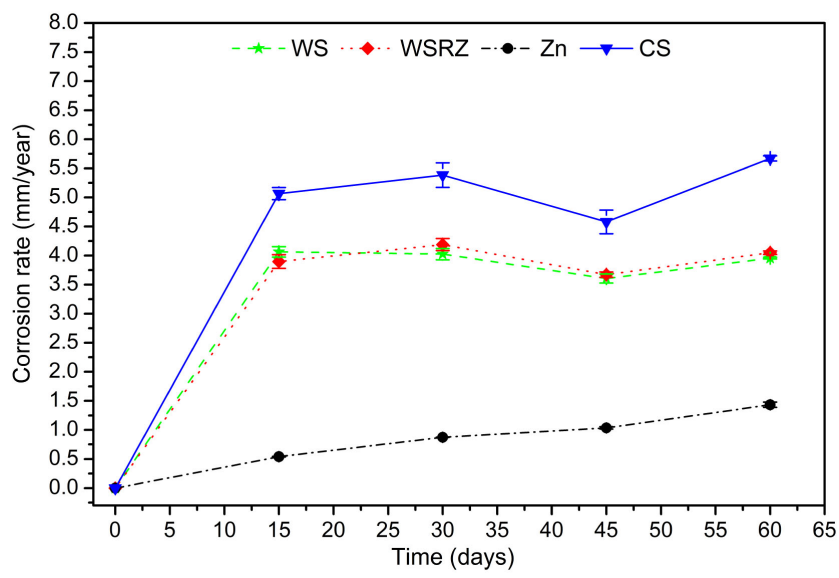

Figure 8. Corrosion rate of the materials in Kesternich test.

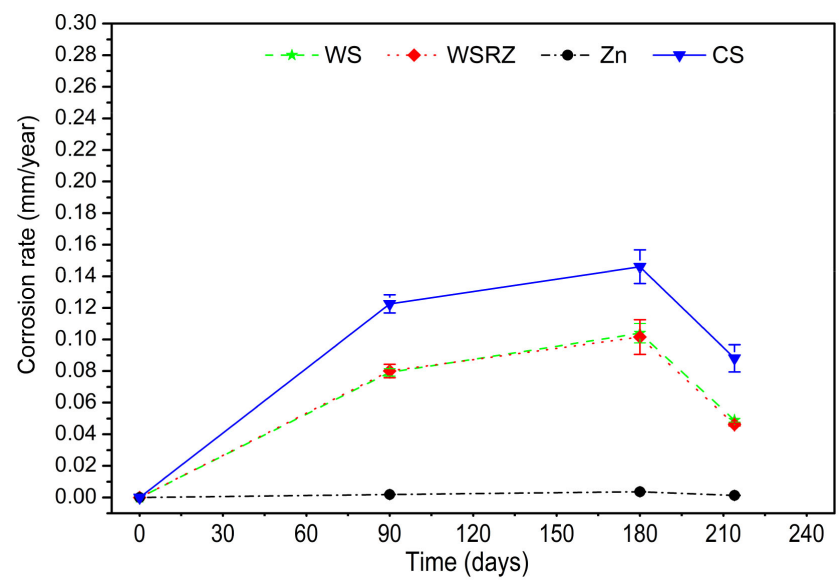

Figure 9. Corrosion rate of the materials in natural exposure.

The fact that the corrosion rates of WS and WSRZ are very similar in all different aggressive media studied strongly suggests that, after depletion of the galvanized layer, the anticorrosive properties of the base metal are preserved. This is corroborated by the electrochemical behaviour of such materials, as no significant distinction on the polarization curves and on the evolution of the poten- 
tial with time was observed. In this sense, galvanizing the weathering steel does not compromise the patina formation. Therefore, the approach to galvanize weathering steel is valid in terms of the additional protection provided to the substrate after the consumption of the zinc layer. Such practice can contribute to the overall anticorrosive performance of galvanized weathering steel, further enhancing the lifetime of structures based on this material.

It is worth noting that, in order to fully confirm the advantages of using galvanized weathering steel, a systematic study regarding the performance of such material during the consumption of the zinc layer must be carried out. In other words, the following question must still be answered: will the galvanized layer be corroded at the same rate when GWS is employed in place of GCS? Electrochemical tests pointed out similar behaviour for both systems; however, this must be confirmed by means of corrosion tests.

\section{Conclusions}

Hot-dip galvanized weathering steel has been used in some structures of the Brazilian electric sector. The experimental research presented in this paper aimed at better understanding the anticorrosive properties of the material, after the zinc layer is corroded, exposing the base iron alloy. As this process can take several years in natural conditions, the removal of the zinc layer was carried out by a controlled chemical pickling process. After that, the anticorrosive properties of the weathering steel were investigated and compared with carbon steel and the original weathering steel (prior to the galvanizing process).

Electrochemical tests and microscopy analysis gave information regarding the zinc layer, its intermetallic phases morphology and its electrochemical behavior. The techniques employed allowed to infer about the zinc layer anticorrosive properties. It was shown that hot-dip galvanizing steels have a thicker layer when the substrate is weathering steel, compared to carbon steel. Electrochemical techniques suggested similar anticorrosive behavior for both galvanized materials. Regarding the substrates, the electrochemical tests pointed out similar anticorrosive properties for the conventional weathering steel and the weathering steel that had its zinc layer removed.

The corrosion tests revealed that, once the zinc layer is consumed, the anticorrosive performance of the weathering steel tends to be the same as in the original material. Given the proper conditions for patina formation, the corrosion rate of weathering steel is considerably lower than carbon steel. Therefore, as galvanizing does not compromise the patina formation, this approach is valid in order to provide an additional protection for the substrate after the zinc coating is consumed. Such practice can further enhance the lifetime of structures employing galvanized weathering steel as their structural material.

\section{Conflicts of Interest}

The authors declare no conflicts of interest regarding the publication of this paper. 


\section{References}

[1] Zhang, Y., Zheng, K., Heng, J. and Zhu, J. (2019) Corrosion-Fatigue Evaluation of Uncoated Weathering Steel Bridges. Applied Sciences, 9, 1-24.

https://doi.org/10.3390/app9173461

[2] Chen, A.-H., Xu, J.-Q., Li, R. and Li, H.-L. (2012) Corrosion Resistance of High Performance Weathering Steel for Bridge Buildings Applications. Journal of Iron and Steel Research, International, 19, 59-63. https://doi.org/10.1016/S1006-706X(12)60128-9

[3] Lein, L.T.H and Hong, H.L. (2013) Characteristics of Corrosion Product Layer Formed on Weathering Steel Exposed to the Tropical Climate of Vietnam. Materials Sciences and Applications, 4, 6-16. https://doi.org/10.4236/msa.2013.47A1002

[4] Morcillo, M., Díaz, I., Chico, B., Cano, H. and Fuente, D. (2014) Weathering Steels: from Empirical Development to Scientific Design. A Review. Corrosion Science, 83, 6-31. https://doi.org/10.1016/j.corsci.2014.03.006

[5] Morcillo, M., Chico, B., Díaz, I., Cano, H. and Fuente, D. (2013) Atmospheric Corrosion Data of Weathering Steels. A Review. Corrosion Science, 77, 6-24. https://doi.org/10.1016/j.corsci.2013.08.021

[6] Marder, A.R. (2000) The Metallurgy of Zinc-Coated Steel. Progress in Materials Science, 45, 191-271. https://doi.org/10.1016/S0079-6425(98)00006-1

[7] Fuente, D., Castaño, J.G. and Morcillo, M. (2007) Long-Term Atmospheric Corrosion of Zinc. Corrosion Science, 49, 1420-1436. https://doi.org/10.1016/j.corsci.2006.08.003

[8] International Organization for Standardization (1992) ISO 1460-Metallic Coatings-Hot Dip Galvanized Coatings on Ferrous Materials-Gravimetric Determination of the Mass per Unit Area. Geneva.

[9] Besseyrias, A., Dalard, F., Rameau, J.J. and Baudin, H. (1995) A Study of Galvanic Corrosion during Coulometric Dissolution of Galvannealed Steel. Corrosion Science, 37, 587-595. https://doi.org/10.1016/0010-938X(94)00155-Y

[10] Queiroz, F.M. and Costa, I. (2007) Electrochemical, Chemical and Morphological Characterization of Galvannealed Steel Coating. Surface and Coatings Technology, 201, 7024-7035. https://doi.org/10.1016/j.surfcoat.2007.01.005

[11] Montoya, P., Díaz, I., Granizo, N., Fuente, D. and Morcillo, M. (2013) An Study on Accelerated Corrosion Testing of Weathering Steel. Materials Chemistry and Physics, 142, 220-228. https://doi.org/10.1016/j.matchemphys.2013.07.009

[12] American Society for Testing and Materials (2002) ASTM G87-Standard Practice for Conducting Moist $\mathrm{SO}_{2}$ Tests. West Conshohocken.

[13] Reis, C.B, Bendinelli, E.V., Ordine, A.P., Amorim, C.C. and Café, Y.H.P. (2016) Análise crítica do ensaio de perda de massa para classificação do grau de agressividade atmosférica. 6th International Corrosion Meeting (Intercorr), Búzios, May 2016, 1-23.

[14] American Society for Testing and Materials (2003) ASTM G1-Standard Practice for Preparing, Cleaning, and Evaluating Corrosion Test. West Conshohocken.

[15] International Organization for Standardization (2009) ISO 8407-Corrosion of Metals and Alloys-Removal of Corrosion Products from Corrosion Test Specimens. Geneva.

[16] American Society for Testing and Materials (2013) ASTM 242-Standard Specifica- 
tion for High-Strength Low-Alloy Structural Steel. West Conshohocken.

[17] American Society for Testing and Materials (2016) ASTM A709-Standard Specification for Structural Steel for Bridges. West Conshohocken.

[18] Foct, J., Perrot, P. and Reumont, G. (1993) Interpretation of the Role of Silicon on the Galvanizing Reaction Based on Kinetics, Morphology and Thermodynamics. Scripta Metallurgica et Materialia, 28, 1195-1200. https://doi.org/10.1016/0956-716X(93)90453-Y

[19] Su, X., Wu, C., Liu, D., Yin, F., Zhu, Z. and Yang, S. (2010) Effect of Vanadium on Galvanizing Si-Containing Steels. Surface and Coatings Technology, 205, 213-218. https://doi.org/10.1016/j.surfcoat.2010.06.037

[20] Jones, D.A. (1996) Principles and Prevention of Corrosion. 2nd Edition, Prentice-Hall International, Upper Saddle River.

[21] Nogueira, T.M.C., Seixas, U.R. and Rios, P.R. (1998) Application of Voltammetric Stripping to a Galvannealed Coating on an Interstitial Free Steel Sheet. ISIJ International, 38, 775-777. https://doi.org/10.2355/isijinternational.38.775 